\title{
CRESCIMENTO INICIAL DE MANGABEIRA (Hancornia speciosa Gomes) EM DIFERENTES MEIOS DE GERMINAÇÃO IN VITRO
}

\author{
Initial growth of mangabeira (Hancornia speciosa Gomes) in different culture medium of \\ in vitro germination
}

\author{
Ana da Silva Lédo', Giuseppe Serra Vieira Seca², Sarah Brandão Santa Cruz Barboza³, \\ Josué Francisco da Silva Junior ${ }^{4}$
}

\begin{abstract}
RESUMO
O objetivo do trabalho foi determinar as condições mais favoráveis para a germinação in vitro de sementes e o crescimento inicial de plântulas de mangabeira. Após assepsia, sementes oriundas de frutos maduros foram inoculadas em tubos de ensaio contendo os seguintes tratamentos: T1-15 mL de meio de cultura MS; T2-15 mL de meio de cultura MS + 2,0 $\mathrm{g} \mathrm{L}^{-1}$ de carvão ativado; T3-15 mL de meio de cultura $1 \frac{1}{2} \mathrm{MS}$; e T4-15 mL de meio de cultura $1 / 2 \mathrm{MS}+2,0 \mathrm{~g} \mathrm{~L}^{-1}$ de carvão ativado. Todos os meios de cultura

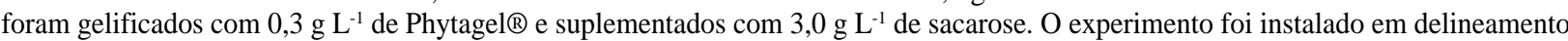
inteiramente casualizado com quatro tratamentos e oito repetições, sendo cada parcela experimental composta de dez tubos de ensaio contendo uma semente cada. Não houve diferença significativa dos tratamentos para a porcentagem de germinação aos 20 dias, que variou de 95 a 100\%. Quanto ao comprimento da raiz principal, observou-se que o meio de cultura constituído de $1 / 2 \mathrm{MS}$ com 2,0 g $\mathrm{L}^{-1}$ de carvão ativado proporcionou maior crescimento quando comparado com os demais tratamentos. Aos 50 dias, não foi observada a formação de plântulas anormais e nem diferenças significativas do comprimento da parte aérea das plântulas. Entretanto, a diluição em $50 \%$ dos sais do meio MS associada à presença de carvão ativado induziu maior crescimento da raiz principal $(8,50 \mathrm{~cm})$ quando comparado com meio MS, na presença $(6,19 \mathrm{~cm})$ ou ausência $(6,00 \mathrm{~cm})$ de carvão ativado.
\end{abstract}

Termos para indexação: Propagação in vitro, meio de cultura, sementes, Apocynaceae.

\begin{abstract}
The objective of this study was to determine the most favorable conditions for the in vitro germination of mangaba seeds and initial development of plantlets. After asepsis, emerging seeds of mature fruits were inoculated in tubes contend the next treatments: T1-15 mL of MS culture medium; T2-15 mL of MS culture medium $+2.0 \mathrm{~g} \mathrm{~L}-1$ of activated charcoal; T3-15 mL of $1 / 2 \mathrm{MS}$ culture medium; and T4-15 mL of $1 / 2 \mathrm{MS}$ culture medium $+2.0 \mathrm{~g} \mathrm{~L}-1$ of activated charcoal. All the culture medium were gellified with $0.3 \mathrm{~g}$ L-1 of Phytagel ${ }^{\circledR}$ and supplemented with $3.0 \mathrm{~g} \mathrm{~L}-1$ of sucrose. The statistical design was completely randomized with four treatments, eight repetitions and ten seeds by experimental unit. There was not significant difference of the treatments for the germination percentage at twenty days, which varied from 95 to $100 \%$. The $1 / 2 \mathrm{MS}$ with $2.0 \mathrm{~g} \mathrm{~L}-1$ of activated charcoal promoted higher growth the main root when compared with the others treatments. After 50 days, abnormal plantlets were not observed and neither significant difference were verified among the length of the aerial part. However, the dilution in 50\% of the MS culture medium associate to the presence of activated charcoal induced higher growth of the main root $(8.50 \mathrm{~cm})$ when compared with MS culture medium in the presence $(6.19 \mathrm{~cm})$ or absence $(6.00 \mathrm{~cm})$ of activated charcoal.
\end{abstract}

Index terms: In vitro propagation, seeds, culture medium, Apocynaceae.

(Recebido em 3 de julho de 2006 e aprovado em 23 de fevereiro de 2007)

\section{INTRODUÇÃO}

A mangabeira (Hancornia speciosa Gomes), nativa dos tabuleiros costeiros, baixada litorânea e cerrados do Brasil, constitui-se em uma das mais importantes matériasprimas para a indústria de sucos e sorvetes do Nordeste e está entre as dez espécies selecionadas como de altíssima prioridade pelo programa Plantas do Futuro do $\mathrm{CNPq} / \mathrm{World}$ Bank/GEF/MMA/Probio, com maior potencial de uso imediato entre as fruteiras nativas da região Nordeste (FERREIRA et al., 2005).

A cultura ainda está em fase de domesticação e, portanto, todos os aspectos relacionados ao seu cultivo ainda necessitam ser melhor estudados, podendo-se citar: propagação vegetativa, seleção de genótipos promissores, desenvolvimento e adaptação de práticas culturais, estudos sobre a fenologia da planta e aspectos relacionados com a

\footnotetext{
'Engenheira Agrônoma, Doutora, Pesquisadora - Embrapa Tabuleiros Costeiros - Avenida Beira Mar, 3250, Praia Treze de Julho - Cx. P. 44 - $49025-040$ Aracaju, SE - analedo@cpatc.embrapa.br

Engenheiro Agrônomo - Núcleo de Pós-Graduação e Estudos em Recursos Naturais/NEREN - Universidade Federal de Sergipe/UFS - Avenida Mal. Rondon, s/n, Jardim Rosa Elze - 49100-000 - São Cristóvão, SE.

${ }^{3}$ Engenheira Agrônoma, Doutora, Pesquisadora Deagro - Embrapa Tabuleiros Costeiros - Avenida Beira Mar, 3250, Praia Treze de Julho - Cx. P. 44 - 49025-040 Aracaju, SE - sarah@cpatc.embrapa.br

${ }^{4}$ Engenheiro Agrônomo, Mestre, Pesquisador - Embrapa Tabuleiros Costeiros - Avenida Beira Mar, 3250, Praia Treze de Julho - Cx. P. 44 - 49025-040 Aracaju, SE - josue@cpatc.embrapa.br
} 
pré e pós-colheita do fruto. Tecnologias de propagação in vitro bem desenvolvidas e/ou adaptadas para a mangabeira são de grande importância para programas de conservação de recursos genéticos e melhoramento genético da mangabeira.

O cultivo in vitro é um procedimento significante na propagação de diferentes espécies. No entanto, alguns problemas têm sido identificados na micropropagação da mangabeira e, dentre eles, destacam-se os contaminantes fúngicos e bacterianos presentes em explantes oriundos de plantas adultas que dificultam o estabelecimento de protocolos de micropropagação (ALOUFA, 2003; LEMOS et al., 2006).

O estabelecimento de protocolos de micropropagação de espécies lenhosas a partir de explantes oriundos de plantas germinadas in vitro é mais viável sob o ponto de vista fisiológico e experimental, devido ao estágio juvenil e capacidade de maior resposta in vitro, possibilitando a condução de inúmeros experimentos (GRATAPAGGLIA \& MACHADO, 1998). Além disso, a obtenção de explantes assépticos resolve problemas como a dificuldade de desinfestar material vegetal e a baixa resposta morfogênica dos tecidos arbóreos adultos (GRIGOLETTO, 1997).

Outro aspecto a ser considerado é que a germinação de sementes in vitro permite, freqüentemente, uma maior germinabilidade das sementes do que em viveiros, provavelmente porque as condições in vitro são mais adequadas aos processos de germinação e desenvolvimento inicial da plântula (NOLETO \& SILVEIRA, 2004).

Diversos trabalhos com a germinação in vitro de mangabeira, variedades botânicas do Nordeste e dos Cerrados, foram realizados (GRIGOLLETO, 1997; LEMOS et al., 2006; MACHADO et al., 2004). Entretanto, aspectos sobre o crescimento inicial in vitro da parte aérea e sistema radicular necessitam ser melhor caracterizados.

Conduziu-se este trabalho, com o objetivo de avaliar o crescimento inicial de plântulas de mangabeira em diferentes meios de germinação in vitro.

\section{MATERIAL E MÉTODOS}

O trabalho foi conduzido no Laboratório de Cultura de Tecidos de Plantas da Embrapa Tabuleiros Costeiros em Aracaju, SE e as sementes foram obtidas de frutos "de vez" de plantas matrizes de população nativa de mangabeira da Estação Experimental de Itaporanga da Embrapa Tabuleiros Costeiros.

As sementes tiveram seus tegumentos removidos para facilitar a germinação e foram desinfestadas com a seguinte seqüência de tratamentos: a) lavagem com solução detergente; b) enxágüe em água destilada para remoção do detergente; c) imersão em fungicida benomil 5,0 $\mathrm{g} \mathrm{L}^{-1}$ por 5 minutos em câmara de fluxo laminar; d) três lavagens com água destilada estéril; e) imersão em álcool etílico 70\% por 10 segundos; f) imersão em solução de hipoclorito de sódio $10 \%$ por 10 minutos e g) três enxágües finais com água destilada estéril (LEMOS, 2003).

As sementes desinfestadas foram inoculadas, em tubos de ensaio contendo os seguintes tratamentos: T1$15 \mathrm{~mL}$ de meio básico MS (MURASHIGE \& SKOOG, 1962); T2-15 mL de meio básico MS + 2,0 $\mathrm{g} \mathrm{L}^{-1}$ de carvão ativado; T3-15 mL de meio básico $1 / 2$ MS; T4-15 mL de meio básico $1 / 2 \mathrm{MS}+2,0 \mathrm{~g} \mathrm{~L}^{-1}$ de carvão ativado. O meio de cultura, em todos os tratamentos, foi gelificado com $0,3 \mathrm{~g} \mathrm{~L}^{-1} \mathrm{de}$ Phytagel ${ }^{\circledR}$ e suplementado com $3,0 \mathrm{~g} \mathrm{~L}^{-1}$ de sacarose. $\mathrm{O}$ $\mathrm{pH}$ foi ajustado para 5,8 e todos os tratamentos submetidos à esterilização em autoclave a $120^{\circ} \mathrm{C}$ durante 15 minutos. As culturas foram mantidas em sala de crescimento com temperatura variando de $25 \pm 2^{\circ} \mathrm{C}$, umidade relativa do ar média em torno de $70 \%$ e fotoperíodo de 16 horas de luz branca fria $\left(52 \mu \mathrm{mol} \mathrm{m}{ }^{-2} \mathrm{~s}^{-1}\right.$ de irradiância).

$\mathrm{O}$ experimento foi instalado em delineamento inteiramente casualizado com quatro tratamentos e oito repetições, sendo cada parcela experimental composta de dez tubos de ensaio contendo uma semente cada. Aos 20 dias da inoculação, foram avaliadas a porcentagem de contaminação, de germinação e comprimento da raiz principal e aos 50 dias a porcentagem de plântulas anormais, o comprimento da parte aérea e da raiz principal. Como plântulas anormais, foram consideradas aquelas que apresentavam ausência ou crescimento atrofiado da parte aérea e/ou do sistema radicular. As médias das variáveis foram submetidas à análise de variância e comparadas pelo teste de Tukey a 5\% de significância.

\section{RESULTADOS E DISCUSSÃO}

O processo de assepsia das sementes foi eficiente, não sendo observada nenhuma contaminação fúngica ou bacteriana ao longo do período de condução do ensaio.

Na terceira semana, após a inoculação, observouse a emissão e o rápido crescimento da radícula (Figuras 1A e 1B), com o posterior desenvolvimento de raízes secundárias (Figura 1C). A partir da quarta semana ocorreu a emergência do epicótilo de coloração roxo-avermelhada, dos nós cotiledonares e do primeiro par de folhas (Figura 1D). A rápida elongação do epicótilo e a expansão do limbo foliar do primeiro par de folhas, foram verificados entre a quarta e a sexta semana após a inoculação (Figura 1E). 


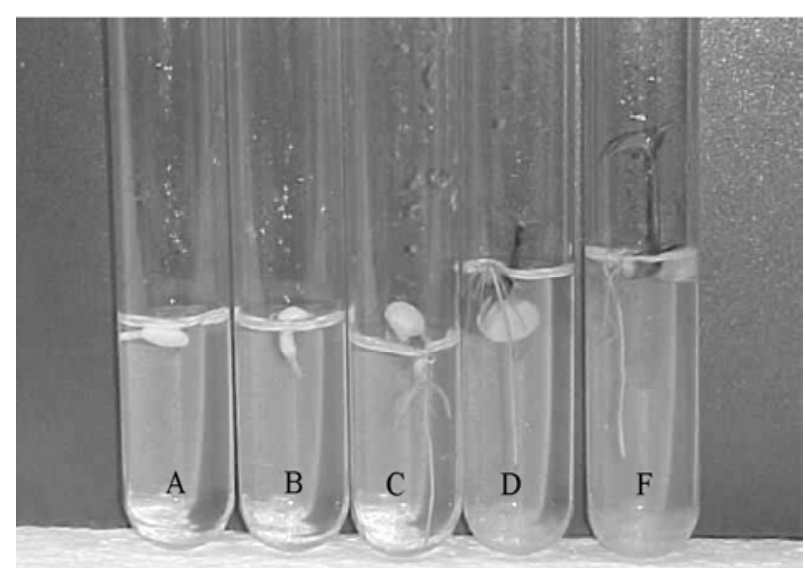

FIGURA 1 - Fases da germinação in vitro de mangabeira. A e B- emissão da radícula; $C$ - crescimento da raiz principal e secundárias; D- lançamento do primeiro par de folhas; e E-elongação do epicótilo e expansão do limbo foliar.

Conforme Tabela 1, não foi constatada diferença significativa dos tratamentos para a porcentagem de germinação aos vinte dias, que variou de 95 a 100\%. Em estudos de germinação de mangabeira sob diferentes condições de cultura in vitro, Pinheiro et al. (2001) obtiveram, aproximadamente, $75 \%$ de germinação em meio MS suplementado com $0,1 \mathrm{mg} \mathrm{L}^{-1}$ de $\mathrm{GA}_{3}$. Lemos (2003) alcançou 62\% em meio MS sem reguladores de crescimento e Sousa et al. (2005), 70\% de germinação em meio básico MS sólido ou líquido, independente de apresentarem ou não o tegumento. Machado et al. (2004), avaliando o potencial de propagação in vitro de
11 matrizes de mangabeira nativas do Cerrado, observaram $92,4 \%$ de germinação em meio MS sem reguladores de crescimento, não se verificando diferenças entre as matrizes.

A porcentagem de germinação de sementes de mangaba em condições de viveiro, em geral, é baixa não só devido à presença de inibidores na polpa como também ao fato de as sementes serem recalcitrantes (LORENZI, 2000).Neste estudo, taxas de germinação acima de $95 \%$ foram obtidas, provavelmente isto se deve à remoção da polpa do fruto e à rápida inoculação das sementes, evitando a desidratação e mantendo a viabilidade da semente.

Quanto ao comprimento da raiz principal, aos 20 dias observou-se que o meio de cultura constituído de $1 / 2 \mathrm{MS} \operatorname{com} 2,0 \mathrm{~g} \mathrm{~L}^{-1}$ de carvão ativado proporcionou maior crescimento quando comparado com os demais tratamentos (Figura 2). Os níveis de nutrientes orgânicos e inorgânicos nos meios de cultivo in vitro influenciam vários processos metabólicos apresentando efeito sobre o crescimento e diferenciação dos tecidos (MALDANER et al., 2006). Provavelmente a redução da concentração de sais em $50 \%$ apresentou efeito positivo no crescimento de tecidos radiculares. Russowski \& Nicoloso (2003), avaliando o efeito da variação de $\mathrm{N}$ e $\mathrm{P}$ do meio MS no crescimento de ginseng brasileiro (Pfaffia glomerata (Spreng.) Pedersen), observaram que o número de raízes e o percentual de enraizamento foi maior na concentração de $\mathrm{N}$ equivalente a $50 \%$ daquela do meio MS. Com espécies lenhosas, o meio MS não se mostra satisfatório em alguns casos e composições mais diluídas em macronutrientes apresentam melhor desempenho (GRATTAPAGLIA \& MACHADO, 1998).

TABELA 1 - Médias da porcentagem de germinação (\% GERM) e comprimento do sistema radicular (CRP) de plântulas de mangabeira sob diferentes condições de cultivo in vitro, aos 20 dias da inoculação.

\begin{tabular}{lcc}
\hline \multicolumn{1}{c}{ Tratamentos } & \% GERM & CRP $(\mathbf{c m})$ \\
\hline $\mathrm{MS}$ & $95,00 \mathrm{a}$ & $1,42 \mathrm{~b}$ \\
$\mathrm{MS}+2,0 \mathrm{~g} \mathrm{~L}^{-1}$ carvão ativado & $100,00 \mathrm{a}$ & $1,65 \mathrm{~b}$ \\
$1 / 2 \mathrm{MS}$ & $95,00 \mathrm{a}$ & $1,69 \mathrm{~b}$ \\
$1 / 2 \mathrm{MS}+2,0 \mathrm{~g} \mathrm{~L}^{-1}$ carvão ativado & $100,00 \mathrm{a}$ & $2,72 \mathrm{a}$ \\
\hline $\mathrm{CV}(\%)$ & 6,71 & 30,24 \\
\hline
\end{tabular}

Médias seguidas pela mesma letra não diferem entre si pelo teste de Tukey a $5 \%$. 
O carvão ativado em concentrações de 0,1 a $2 \%$ pode ser benéfico em alguns casos. Fisicamente, ele simula a condição de escuro, no qual as raízes normalmente se desenvolvem melhor pela redução da incidência de luz na zona de crescimento ativo do sistema radicular, além de adsorver substâncias tóxicas, principalmente fenóis e/ou quinonas que podem afetar o desenvolvimento do explante (GRATTAPAGLIA \& MACHADO, 1998).

Não foi observada a formação de plântulas anormais e nem diferenças significativas do comprimento

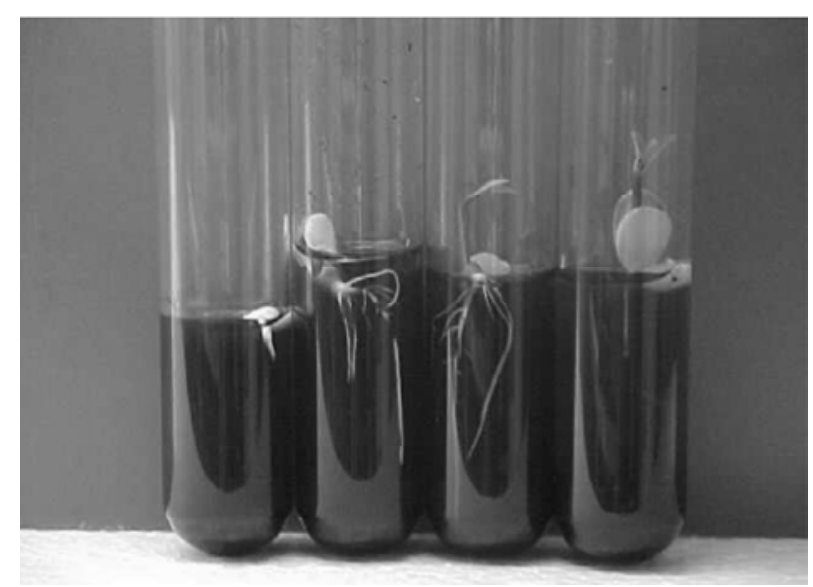

FIGURA 2 - Desenvolvimento do sistema radicular de plântulas de mangaba em meio de cultura $1 / 2 \mathrm{MS}$ com $2 \mathrm{~g} \mathrm{~L}^{-1}$ de carvão ativado. da parte aérea das plântulas em todos os tratamentos aos 50 dias de inoculação (Tabela 2). A diluição em $50 \%$ dos sais do meio de cultura MS associada à presença de carvão ativado induziu maior crescimento longitudinal da raiz principal $(8,50 \mathrm{~cm})$ quando comparado com meio MS, na presença $(6,19 \mathrm{~cm})$ ou ausência $(6,00 \mathrm{~cm})$ de carvão ativado.

Embora, estatisticamente, não tenha sido detectada diferença significativa entre os valores de comprimento da parte aérea, a adição de carvão ativado em meio de cultura $1 \frac{1}{2}$ MS e MS, aumentou em 55 e $27 \%$ o comprimento da parte aérea, respectivamente. Este fato se deve a resposta do efeito benéfico do carvão ativado no sistema radicular, proporcionando um maior alongamento da parte aérea.

Observou-se um desenvolvimento balanceado da parte aérea e do sistema radicular das plântulas de mangabeira em todos os tratamentos. Segundo Peres \& Kerbauy (2000), o equilíbrio no desenvolvimento entre caule e raízes é vantajoso considerando que ambos possuem funções complementares na sobrevivência geral das plantas.

Os resultados obtidos demonstraram a eficiência da desinfestação das sementes e da germinação e crescimento inicial in vitro na obtenção de plântulas normais e vigorosas de mangabeira. Os resultados poderão ser aplicados na obtenção de explantes juvenis e assépticos para a micropropagação, na propagação sexuada in vitro e na produção de porta-enxertos em futuros trabalhos de microenxertia.

TABELA 2 - Médias da porcentagem de plântulas normais (\% PN), do comprimento da parte aérea (CPA) e do sistema radicular (CRP) e da relação CRP/CPA de plântulas de mangabeira sob diferentes condições de cultivo in vitro, aos 50 dias da inoculação.

\begin{tabular}{lcccc}
\hline \multicolumn{1}{c}{ Tratamentos } & \% PN & CPA $(\mathbf{c m})$ & CRP $(\mathbf{c m})$ & Relação CRP/CPA \\
\hline MS & 100 & $6,25 \mathrm{a}$ & $6,00 \mathrm{c}$ & 0,96 \\
$\mathrm{MS}+2,0 \mathrm{~g} \mathrm{~L}^{-1}$ carvão ativado & 100 & $7,94 \mathrm{a}$ & $6,19 \mathrm{c}$ & 0,78 \\
$1 / 2 \mathrm{MS}$ & 100 & $6,03 \mathrm{a}$ & $7,03 \mathrm{ab}$ & 1,17 \\
$1 / 2 \mathrm{MS}+2,0 \mathrm{~g} \mathrm{~L}^{-1}$ carvão ativado & 100 & $9,38 \mathrm{a}$ & $8,50 \mathrm{a}$ & 0,91 \\
\hline CV $(\%)$ & - & 34,14 & 23,55 & \\
\hline
\end{tabular}

Médias seguidas pela mesma letra não diferem entre si pelo teste de Tukey a 5\%. 


\section{CONCLUSÕES}

Todos os meios de cultura testados são eficientes para a germinação in vitro de sementes e formação de plântulas normais de mangabeira.

O meio de cultura MS com metade da concentração salina, acrescido de 2,0 $\mathrm{g} \mathrm{L}^{-1}$ de carvão ativado proporciona $100 \%$ de germinação e bom desenvolvimento da parte aérea e sistema radicular de plântulas de mangabeira in vitro.

\section{AGRADECIMENTOS}

À Embrapa, pelo aporte de recursos financeiros e ao Conselho Nacional de Pesquisa Científica- CNPq, pela concessão de bolsa PIBIC.

\section{REFERÊNCIAS BIBLIOGRÁFICAS}

ALOUFA, M. A. I. Multiplicação e conservação in vitro de mangabeira. In: SIMPÓSIO BRASILEIRO SOBRE A CULTURA DA MANGABA, 1., 2003, Aracaju. Anais... Aracaju: Embrapa Tabuleiros Costeiros, 2003. CD-ROM.

FERREIRA, E. G.; LEMOS, E. E. P.; SOUZA, F. X.; LOURENÇO, I. P.; LEDERMAN, I. E.; BEZERRA, J. E. F.; SILVA JUNIOR, J. F. da; BARROS, L. M.; RUFINO, M. S. M.; OLIVEIRA, M. E. B. Frutíferas. In: SAMPAIO, E. V. S. B.; PAREYN, F. G. C.; FIGUEIRÔA, J. M. de; SANTOS JUNIOR, A. G. (Orgs.). Espécies da flora nordestina de importância econômica potencial. Recife: Associação Plantas do Nordeste, 2005. p. 49-100.

GRIGOLETTO, E. R. Micropropagação de Hancornia speciosa Gomez (Mangabeira). 1997. 73 f. Dissertação (Mestrado em Botânica) - Universidade de Brasília, Brasília, DF, 1997.

GRATTAPAGLiA, D.; MACHADO, M. A. Micropropagação. In: TORRES, A. C.; CALDAS, L. S.; BUSO, J. A. (Eds.). Cultura de tecidos e transformação genética de plantas. Brasília, DF: Embrapa-SPI/EmbrapaCNPH, 1998. p. 183-260.

LEMOS, E. E. P. de. Estratégias para a multiplicação clonal da mangabeira em Alagoas. In: SILPÓSIO BRASILEIRO SOBRE A CULTURA DA MANGABA, 1., 2003, Aracaju. Anais... Aracaju: Embrapa-CPATC/MAPA, 2003. CD-ROM.

LEMOS, E. E. P. de; COSTA, M. A. P. de C.; ALOUFA, M. A. I.; LEDO, A. da S. Micropropagação. In: SILVA
JUNIOR, J. F. da; LEDO, A. da S. (Eds.). A cultura da mangaba. Aracaju: Embrapa Tabuleiros Costeiros, 2006. p. 125-133.

LORENZI, H. Árvores brasileiras: manual de identificação e cultivo de plantas arbóreas nativas do Brasil. 3. ed. Nova Odessa: Plantarum, 2000. v. 1, 352 p.

MACHADO, L. de L.; RAMOS, M. L. G.; CALDAS, L. S.; VIVALDI, L. J. Seleção de matrizes e clones de mangabeira para o cultivo in vitro. Pesquisa Agropecuária Brasileira, Brasília, v. 39, n. 5, p. 431-435, maio 2004.

MALDANER, J.; NICOLOSO, F. T.; SANTOS, E. S. dos; FLORES, R.; SKREBSKY, E. C. Sacarose e nitrogênio na multiplicação in vitro de Pfaffia glomerata (Spreng.) Pedersen. Ciência Rural, Santa Maria, v. 36, n. 4, p. 12011206, jul./ago. 2006.

MURASHIGE, T.; SKOOG, F. A revised medium for rapid growth and bioassays with tobacco tissue cultures. Physiologia Plantarum, Copenhagen, v. 15, n. 3, p. 473497, Mar. 1962.

NOLETO, L. G.; SILVEIRA, C. E. dos S. Micropropagação de copaíba. Revista Biotecnologia Ciência \& Desenvolvimento, Rio de Janeiro, v. 33, p. 109-120, jul./dez. 2004.

PERES, L. E. P.; KERBAUY, G. B. Controle hormonal do desenvolvimento de raízes. Revista Universa, Brasília, v. 8, n. 1, p. 181-196, mar. 2000.

PINHEIRO, C. S. R.; MEDEIROS, D. N. de; MACÊDO, C. E. C. de; ALOUFA, M. A. I. Germinação in vitro de mangabeira (Hancornia speciosa Gomez) em diferentes meios de cultura. Revista Brasileira de Fruticultura, Jaboticabal, v. 23, n. 2, p. 413-416, ago. 2001.

RUSSOWSKI, D.; NICOLOSO, F. T. Nitrogênio e fósforo no crescimento de plantas de Ginseng Brasileiro [Pfaffia glomerata (Spreng.) Pedersen] cultivadas in vitro. Ciência Rural, Santa Maria, v. 33, n. 1, p. 57-63, 2003.

SOUSA, C. da S.; SILVA, S. A.; COSTA, M. A. P. C. Mangaba: perspectivas e potencialidades. Revista Bahia Agrícola, Salvador, v. 7, n. 1, p. 29-31, set. 2005. 